\title{
LARVICIDAL AND ENZYME INHIBITORY EFFECTS OF ACALYPHA FRUTICOSA (F.) AND CATHARANTHUS ROSEUS L (G) DON. LEAF EXTRACTS AGAINST CULEX QUINQUEFASCIATUS (SAY.) (DIPTERA: CULICIDAE)
}

\author{
PAVUNRAJ M ${ }^{1 *}$, RAMESH V ${ }^{2}$, SAKTHIVELKUMAR $\mathbf{S}^{3}$, VEERAMANI $\mathrm{V}^{3}$, JANARTHANAN $\mathbf{S}^{3}$ \\ ${ }^{1}$ Department of Zoology, Vivekananda College, Madurai Kamaraj University, Tiruvedakam West, Madurai, Tamil Nadu, India. \\ ${ }^{2}$ Department of Botany, Vivekananda College, Madurai Kamaraj University, Tiruvedakam West, Madurai, Tamil Nadu, India. ${ }^{3}$ Department \\ of Zoology, University of Madras, Guindy Campus, Chennai, Tamil Nadu, India. Email: mpavunraj@gmail.com
}

Received: 04 November 2016, Revised and Accepted: 30 November 2016

ABSTRACT

Objective: The prime objective of this study is to evaluate the larvicidal and enzyme inhibitory effects of Acalypha fruticosa and Catharanthus roseus leaf extracts against Culex quinquefasciatus.

Methods: Insecticidal susceptibility tests were carried out using the World Health Organization standard method, and the mortality was observed after 24 hrs exposure.

Results: The tested extracts showed a significant larvicidal activity depending on the dose of the plant extracts. However, maximum larval mortality was detected in ethyl acetate extract of $A$. fruticosa with a lethal concentration $\left(\mathrm{LC}_{50}\right)$ value of $253.08 \mathrm{ppm}$ and $\left(\mathrm{LC}_{90}\right)$ value of $455.40 \mathrm{ppm}$ followed by hexane extract of $C$. roseus with $\mathrm{LC}_{50}$ value of $645.33 \mathrm{ppm}$ and $\mathrm{LC}_{90}$ value of $1452.88 \mathrm{ppm}$ against the larvae of $C$. quinquefasciatus. In control, there were five different fractions of $\alpha$-carboxylesterases resolved in the gel with the mobilities ranging between 0.14 and 0.66 . $\beta$-carboxylesterase isozyme profile of larvae treated with hexane extract of $A$. fruticosa showed higher enzyme activities by way of intense staining of fractions both at $1 / 4$ and $1 / 10 \mathrm{LC}_{50}$ value of $48 \mathrm{hrs}$ treatments. A. fruticosa ethyl acetate extract, and $C$. roseus hexane extract exposed larvae indicated increased quantities of $\beta$-Est4/5 isozymes in the concentration of $1 / 4$ and $1 / 10$ of $\mathrm{LC}_{50}$ value of 24 hrs treatment when compared to control. The protein quantity in the majority of treatments decreased compared to control.

Conclusion: The results revealed that the organic leaf extract of A. fruticosa and C. roseus had significant larvicidal and enzyme inhibitory effects against $C$. quinquefasciatus.

Keywords: Acalypha fruticosa, Catharanthus roseus leaves extract, $\beta$-carboxylesterase, Culex quinquefasciatus, Lethal concentration ${ }_{50}$.

(C) 2017 The Authors. Published by Innovare Academic Sciences Pvt Ltd. This is an open access article under the CC BY license (http://creativecommons. org/licenses/by/4. 0/) DOI: http://dx.doi.org/10.22159/ajpcr.2017.v10i3.16029

\section{INTRODUCTION}

Mosquitoes are medically most important and responsible for transmitting the vector-borne diseases, parasites, and pathogens which continue to have a devastating impact on human beings, public hygiene and ecological perspectives [1]. Mosquitoes under the genus Culex are the vectors of encephalitis and filariasis [2]. Frequent outbreaks of these diseases result in restricting the socioeconomic status in developing countries in the tropical and subtropical belts. Considerable economic, ecological, and public health impacts of vector-borne diseases are expected to continue, given limited domestic and international capabilities for detecting, identifying, and addressing likely epidemics. It is estimated that every year at least 500 million people in the world suffer from one or the other tropical diseases that include malaria, lymphatic filariasis, schistosomiasis, dengue, trypanosomiasis, and leishmaniasis. 1-2 million deaths are reported annually due to malaria worldwide. Lymphatic filariasis affects at least 120 million people in 73 countries in Africa, India, Southeast Asia, and Pacific Islands. Synthetic insecticides are effective in controlling mosquitoes, but their environmental consequences are unpredictable. In the context of everincreasing trend to use more powerful synthetic insecticides to achieve immediate results in the control of mosquitoes, an alarming increase of physiological resistance in the vectors, its increased toxicity to nontarget organism and high costs are noteworthy [3]. Most of the synthetic chemicals are expensive and destructive to the environment and also toxic to humans, animals, and other beneficial organisms. Besides, they are non-selective and harmful to other beneficial organisms. Therefore, effective and low-cost alternate vector control strategies, especially are extremely imperative [4,5]. Use of different parts of locally available plants and their various products in the control of mosquitoes have been accepted globally by numerous researchers.

Phytochemicals derived from plant sources can act as larvicides, insect growth regulators, repellents, and ovipositional attractants and also have deterrent actions as observed by many researchers [6-8]. The larvicidal properties of indigenous plants have also been documented in many parts of India along with the repellent and anti-juvenile hormones activities [9]. Traditionally, plants and their derivatives were used to kill mosquitoes and other household and agricultural pests. In all probability, these plants used to control insects contained insecticidal phytochemicals that were predominantly secondary compounds produced by plants to protect themselves against herbivorous insects $[10,11]$.

Esterase is an enzyme that played a significant role both physiologically and biochemically during any stress on insects. They are excellent key enzymes involved in the metabolism of hormones [12,13], digestion [14], and resistance to insecticides. Esterases are considered an important tool for analysis of genetic differentiation and evolutionary relationship of insects [12]. These enzymes are tissue specific in insects [15] and are closely linked with morphological, physiological, or biochemical ontogenetic alterations [16]. FfrenchConstant et al. [17] described an electrophoretic technique, based on patterns of esterase bands on polyacrylamide gel (PAGE) for 
distinguishing large samples of Myzus antirrhinic from susceptible or resistant populations of the closely related species of Myzus persicae. In addition to the insecticidal activity, most of toxicological approaches on botanical insecticides have been focused on inhibition or induction of detoxifying enzymes such as carboxylesterase, glutathione-S-transferase and cytochrome P450. Rachokarn et al. [18] reported similar results on different enzymes, that is, carboxylesterase activity had a tendency to be induced after treated with Amaranthus viridis extracts. These inductances of detoxifying enzyme suggest a possibility on the development of resistance against the extracts as shown in many reports on increased induction in detoxifying enzyme activity and discussed on development of resistance of many insect pests [19-22]. In the present work, both quantitative and qualitative analyses of esterases were undertaken to assess the efficacy of hexane, ethyl acetate, and methanol extracts of Acalypha fruticosa and Catharanthus roseus leaves against esterase induction/activity in the fourth-instar larvae of Culex quinquefasciatus. With this background, the present investigation was undertaken to assess the efficacy of various solvent extracts of the leaves of very well-known Indian medicinal plants $A$. fruticosa and $C$. roseus against the fourth-instar larvae of $C$. quinquefasciatus.

\section{MATERIALS AND METHODS}

\section{Materials}

\section{Plant collection and preparation of leaf extracts}

The healthy leaves of the selected plant species of $A$. fruticosa (Euphorbiaceae) and C. roseus (Apocynaceae) were collected during 2012 from in and around Chennai, Tamil Nadu, India. Plant specimens were identified by plant taxonomists and standard flora. The leaves were shade dried at room temperature and coarsely powdered in a powdering machine. A total of $200 \mathrm{~g}$ powder of the plant was extracted sequentially with increasing polarity of hexane, ethyl acetate, and methanol at room temperature for 1 week with occasional shaking in an aspirator bottle. The extract was filtered through Watmann No.1 filter paper and evaporated in vacuum evaporator.

\section{Rearing of mosquitoes}

The test was carried out against laboratory reared $C$. quinquefasciatus mosquitoes free of exposure to insecticides and pathogens. Cyclic generations of $C$. quinquefasciatus were maintained at $25-29^{\circ} \mathrm{C}$ and $80-90 \%$ R.H in the insectarium. Larvae were fed on larval food (powdered dog biscuits and yeast in the ratio of 3:1) and adult mosquitoes on ten percent glucose solution. Adult female mosquitoes were periodically blood-fed on restrained albino mice for egg production.

\section{Larval toxicity test}

A laboratory reared colony of $C$. quinquefasciatus larvae was used for the larvicidal activity. Twenty individuals of fourth-instar larvae were kept in a $500 \mathrm{ml}$ glass beaker containing $249 \mathrm{ml}$ of decholorinated water and desired concentration of $C$. roseus and A. fruticosa leaf extracts in $1 \mathrm{ml}$ of acetone with Tween-20 (1\%). Larval food was given for the test larvae. At each tested concentration, two to five trials were made, and each trial includes five replicates. The negative control was setup by mixing $1 \mathrm{ml}$ of acetone with $249 \mathrm{ml}$ of dechlorinated water. The larvae exposed to dechlorinated water without acetone served as positive control. The control mortalities were corrected by using Abbott's formula [23].

$$
\text { Percentage mortality }=\frac{\text { Number of dead larvae }}{\text { Number of larvae introduced }} \times 100
$$

\section{Statistical analysis}

All data were subjected to analysis of variance. The means were separated using Duncan's multiple range tests by Alder and Rossler [24]. The average larval mortality data were subjected to probit analysis for calculating lethal concentration $\left(\mathrm{LC}_{50}\right)$ and $\mathrm{LC}_{90}$. Values were calculated using the Finney [25] method. Statistical software package 9.0 version was used. Results with $\mathrm{p}<0.05$ were considered statistically significant.
Preparation of whole body homogenates of larvae and pupae for esterase analyses

The level of esterase enzymes (against both alpha and beta naphthyl acetates as substrates) were estimated in the fourth-instar larvae of C. quinquefasciatus subjected to hexane, ethyl acetate, and methanol extracts of A. fruticosa and C. roseus leaves. A suitable control was also maintained. After treatment, the larvae were removed from the treatment tray, washed with double distilled water, and the adhering water was completely removed from the body by blotting with tissue paper. The larvae ( 25 individuals) from each of the treatments were transferred separately to eppendorf tubes and homogenized using a teflon hand homogenizer in $150 \mu$ l of ice-cold phosphate buffer $(20 \mathrm{mM}$, $\mathrm{pH}$ 7.0) for extraction of esterases. The whole body homogenates were centrifuged at $10000 \mathrm{rpm}$ at $4^{\circ} \mathrm{C}$ for 20 minutes, and the clear supernatants were collected for further esterase assays.

\section{Quantitative analyses of biochemical constituents}

The impact of exposure of plant extracts on fourth-instar larvae of C. quinquefasciatus was quantitatively analyzed in response to the level of protein and expressed as unit enzyme activity per mg protein.

\section{Determination of protein concentration}

Protein concentrations in the larval homogenates were estimated following the method of Bradford [26]. To $5 \mu$ l of protein or blank solution, $195 \mu \mathrm{l}$ of Bradford reagent was added and mixed well. The optical density was read between 5 and 20 minutes after addition of protein reagent at $595 \mathrm{~nm}$. Protein concentration per $\mathrm{ml}$ of the test sample was calculated as follows.

Protein concentration in the sample $\left(\frac{\mathrm{mg}}{\mathrm{ml}}\right)=$

$\frac{\text { OD of sample }}{\text { OD of standard }} \times$ Concentration of standard $(40 \mu \mathrm{g})$

\section{Estimation of carboxylesterase activity}

The carboxylesterase activity in the whole body homogenates was measured by the modified method of Van Asperen [27] as described by Argentine and James [28].

\section{Estimation of $\alpha$-carboxylesterase activity}

A volume of $10 \mu \mathrm{l}$ of whole body homogenate of larvae was incubated with $198 \mu \mathrm{l}$ of $20 \mathrm{mM}$ sodium phosphate buffer ( $\mathrm{pH} 7.0$ ) containing 250 $\mu \mathrm{M}$ of $\alpha$-naphthyl acetate for 10 minutes at RT. After incubation, $50 \mu \mathrm{l}$ of freshly prepared $0.3 \%$ fast blue B salt in 3.3\% SDS were added to stop the enzymatic reaction and allowed to develop color for 15 minutes at RT. The optical density of samples was read at $430 \mathrm{~nm}$ against the blank consisting of same reagents and buffer substituted for the homogenate. The level of $\alpha$-carboxylesterase activity was calculated and expressed as $\mu \mathrm{M} /$ minute/mg protein

\section{Estimation of $\beta$-carboxylesterase activity}

The whole body homogenate of larvae was first diluted 3 times with sodium phosphate buffer $(20 \mathrm{mM}, \mathrm{pH} 7.0)$, and $100 \mu \mathrm{l}$ of diluted homogenate was incubated with $1 \mathrm{ml}$ of sodium phosphate buffer ( $20 \mathrm{mM}$, pH 7.0) containing $250 \mu \mathrm{M}$ of $\beta$-naphthyl acetate for 10 minutes at RT. After incubation, $400 \mu \mathrm{l}$ of freshly prepared $0.3 \%$ fast blue B salt in $3.3 \%$ SDS were added to stop the enzymatic reaction and allowed to develop color for 15 minutes at RT. Blank consisted of same reagents and buffer instead of homogenate. The optical density of samples was read at $580 \mathrm{~nm}$ against the blank. The level of $\beta$-carboxylesterase activity was calculated and expressed as $\mu \mathrm{M} /$ minute/mg protein.

\section{Qualitative analyses of esterase enzymes using native PAGE}

The effect of exposure of fourth-instar larvae to various solvent extracts of plants was qualitatively analyzed by native-PAGE with esterase enzymes.

\section{Native-PAGE}

The profiles of esterase enzymes in the whole body homogenates of fourth-instar larvae were analyzed in discontinuous PAGE under non- 
denaturing conditions following Maurer [29]. This was performed using $3 \%$ stacking gel (pH 6.7) and 7\% separating gel (pH 8.9) in Tris-glycine buffer (pH 8.3). Samples of the whole body homogenates (each $80 \mu \mathrm{l}$ ) of control and experimental larvae were electrophoresed at a constant current of $3 \mathrm{~mA}$ per sample at $10^{\circ} \mathrm{C}$ on a slab gel $(170 \times 150 \times 1.5 \mathrm{~mm})$. After electrophoresis, the gels were suitably stained for detection of esterase activity.

\section{Detection of carboxylesterase activity}

The electrophoretically separated bands with esterase activity were detected in the gel following the method of Argentine and James [28]. Accordingly, the gel was first incubated with phosphate buffer $(20 \mathrm{mM}$, $\mathrm{pH} 7.0$ ) for 15 minutes at RT. After decanting the buffer, the gel was then re-incubated for 30 minutes at RT with freshly prepared $\alpha$-naphthyl acetate + fast blue $B$ solution for detection of $\alpha$-carboxylesterase or $\beta$-naphthyl acetate + fast blue $B$ solution for detection of $\beta$-carboxylesterase. The gels were washed with distilled water and stored in $7 \%$ acetic acid. After the electrophoresis, the destained gel was measured for relative mobility of protein bands. Relative mobility is the distance migrated by a band divided by the distance migrated by the dye (i.e., dye front).

\section{Densitometry analysis of esterase isozyme}

All the native PAGE gels performed for $\alpha$-carboxylesterase or $\beta$-carboxylesterase banding pattern were subjected to densitometry analysis using Image J 1.46r software developed by National Institutes of Health (NIH), U.S. Department of Health and Human Service.

\section{RESULTS}

The results of larvicidal activity of hexane, ethyl acetate and methanol extracts of $A$. fruticosa and $C$. roseus are summarized in Table 1 . The effect on larval mortality was concentration dependent. It has observed that the ethyl acetate extracts of $A$. fruticosa possess maximum larvicidal activity against $4^{\text {th }}$ instar larvae of $C$. quinquefasciatus. The percentage mortality of larvae treated with $A$. fruticosa recorded with $87.25 \%$ at $5 \%$ concentration followed by hexane $(65.0 \%)$ and methanol (57.50) extracts compared with untreated control. The results of the larvicidal activities of different crude extracts of $C$. roseus in hexane against $C$. quinquefasciatus was $62.50 \%$ at $5 \%$ concentration followed by extracts of methanol (58.75\%) and ethyl acetate (43.75\%) when compared with untreated control. No mortality was recorded in various replicates of control.

The results of the $\mathrm{LC}_{50}$ and $\mathrm{LC}_{90}$ values of the plant extracts after $24 \mathrm{hrs}$ against the larvae of $C$. quinquefasciatus are shown in Table 2.

The ethyl acetate leaf extract of $A$. fruticosa was found to be effective with a $\mathrm{LC}_{50}$ value of $253.08 \mathrm{ppm}$ and $\mathrm{LC}_{90}$ value of $455.40 \mathrm{ppm}$ followed by extracts of hexane with $\mathrm{LC}_{50}$ value of $429.99 \mathrm{ppm}$ and $\mathrm{LC}_{90}$ value of $774.45 \mathrm{ppm}$ and methanol with $\mathrm{LC}_{50}$ value of $574.82 \mathrm{ppm}$ and $\mathrm{LC}_{90}$ value of $1035.00 \mathrm{ppm}$ against $4^{\text {th }}$ instar larvae of $C$. quinquefasciatus. The efficacy of hexane extract of $C$. roseus was most active with $\mathrm{LC}_{50}$ value of $645.33 \mathrm{ppm}$ and $\mathrm{LC}_{90}$ value of $1452.88 \mathrm{ppm}$ followed by extracts of methanol with $\mathrm{LC}_{50}$ value of $715.39 \mathrm{ppm}$ and $\mathrm{LC}_{90}$ value of $1287.54 \mathrm{ppm}$ and ethyl acetate with $\mathrm{LC}_{50}$ value of $1370.06 \mathrm{ppm}$ and $\mathrm{LC}_{90}$ value of
2089.43 ppm against the larvae of $C$. quinquefasciatus. This study showed the larvicidal potency of various solvent extracts of leaves of these two plants against $C$. quinquefasciatus. Thus A. fruticosa and $C$. roseus could be exploited further for identification of specific larvicidal agents.

Esterase enzyme gel electrophoresis was carried out using 7\% PAGE (Native-PAGE) with $\alpha$ - and $\beta$-naphthyl acetates as staining substrates for all the plant extracts treated mosquito larvae of $C$. quinquefasciatus. In control, there were five different fractions of $\alpha$-carboxylesterases resolved in the gel with the mobilities ranging between 0.14 and 0.66 . On exposure of the larvae to different plant extracts, intensity of staining of various enzyme fractions was decreased with disappearance of at least two or three $\alpha$-carboxylesterase enzyme fractions (Fig. 1). On the contrary, the staining intensity of one slow moving fraction $\alpha$-Est 1 with a mobility of 0.49 was increased significantly or maintains the same level in all experimental groups when compared to control. A similar trend was observed in the larvae of $C$. quinquefasciatus treated against ethyl acetate and hexane extracts of $A$. fruticosa and hexane and methanol extracts of C. roseus (Fig. 1). The relative mobility of $\beta$-carboxylesterase isozyme profile of larvae of $C$. quinquefasciatus treated against ethyl acetate extract of $A$. fruticosa revealed four different enzyme fractions in control and three fractions in $24 \mathrm{hrs}$ treatment and four fractions in $48 \mathrm{hrs}$ treatment (Fig. 2).

Among various treatments, the staining intensities of various enzyme fractions were significantly higher in $24 \mathrm{hrs}$ and $48 \mathrm{hrs}$ treatments of ethyl acetate at $1 / 4$ of $\mathrm{LC}_{50}$ value at $24 \mathrm{hrs}$ treatment of $1 / 10$ of $\mathrm{LC}_{50}$ value at $24 \mathrm{hrs}$ treatment. Likewise, $\beta$-carboxylesterase isozyme



Fig. 1: $\alpha$-Carboxylesterase isozyme pattern of Culex quinquefasciatus upon exposure to different medicinal plant extracts. C: Control, 1: 1/4 dilution $24 \mathrm{hrs}$, 2: 1/4 dilution $48 \mathrm{hrs}$, 3: 1/10 dilution $24 \mathrm{hrs}, 4: 1 / 10$ dilution $48 \mathrm{hrs}$

Table 1: Percent larvicidal activity of leaf extracts of Acalypha fruticosa and Catharanthus roseus against fourth instar larvae of Culex quinquefasciatus

\begin{tabular}{llllllll}
\hline Name of the plants & Solvent & Control & \multicolumn{5}{l}{ Concentration in ppm } \\
\cline { 3 - 7 } & & & $\mathbf{1 0 0}$ & $\mathbf{1 2 5}$ & $\mathbf{2 5 0}$ & $\mathbf{5 0 0}$ & $\mathbf{1 0 0 0}$ \\
\hline A. fruticosa & Hexane & $0 \pm 0^{\mathrm{a}}$ & $13.75 \pm 0.95^{\mathrm{bc}}$ & $21.25 \pm 1.01^{\mathrm{bc}}$ & $35.00 \pm 1.91^{\mathrm{c}}$ & $48.11 \pm 1.15^{\mathrm{d}}$ & $65.00 \pm 0.22^{\mathrm{b}}$ \\
& Ethyl acetate & $0 \pm 0^{\mathrm{a}}$ & $25.00 \pm 0.12^{\mathrm{c}}$ & $33.75 \pm 1.36^{\mathrm{d}}$ & $53.75 \pm 1.20^{\mathrm{c}}$ & $65.75 \pm 1.33^{\mathrm{c}}$ & $87.25 \pm 1.52^{\mathrm{c}}$ \\
& Methanol & $0 \pm 0^{\mathrm{a}}$ & $10.00 \pm 1.41^{\mathrm{b}}$ & $20.00 \pm 1.41^{\mathrm{b}}$ & $16.25 \pm 0.83^{\mathrm{a}}$ & $46.00 \pm 0.56^{\mathrm{b}}$ & $57.50 \pm 0.51^{\mathrm{ab}}$ \\
C. roseus & Hexane & $0 \pm 0^{\mathrm{a}}$ & $12.25 \pm 0.77^{\mathrm{b}}$ & $18.50 \pm 1.77^{\mathrm{a}}$ & $24.75 \pm 1.65^{\mathrm{b}}$ & $44.50 \pm 1.02^{\mathrm{b}}$ & $62.50 \pm 0.44^{\mathrm{a}}$ \\
& Ethyl acetate & $0 \pm 0^{\mathrm{a}}$ & $11.25 \pm 1.59^{\mathrm{b}}$ & $16.25 \pm 1.30^{\mathrm{a}}$ & $23.75 \pm 0.36^{\mathrm{b}}$ & $28.75 \pm 1.07^{\mathrm{a}}$ & $43.75 \pm 1.20^{\mathrm{a}}$ \\
& Methanol & $0 \pm 0^{\mathrm{a}}$ & $10.75 \pm 1.41^{\mathrm{b}}$ & $27.5 \pm 1.54^{\mathrm{c}}$ & $42.50 \pm 0.96^{\mathrm{b}}$ & $52.50 \pm 0.63^{\mathrm{d}}$ & $58.75 \pm 1.38^{\mathrm{a}}$ \\
\hline
\end{tabular}

Values carrying same alphabets in a column are not statistically significant by Turkey's Test at $p=0.05 \%$ level 
Table 2: Probit analysis on larvicidal efficacy of Acalypha fruticosa and Atharanthus roseus against fourth instar larvae of Culex quinquefasciatus

\begin{tabular}{|c|c|c|c|c|c|}
\hline Name of the plants & Solvent extract & $\mathbf{L C}_{50}$ & $\mathrm{LC}_{90}$ & Chi-square Value & Regression value \\
\hline \multirow[t]{3}{*}{ A. fruticosa } & Hexane & 429.99 & 774.45 & $0.82^{*}$ & 2.72 \\
\hline & Ethyl acetate & 253.08 & 455.40 & $1.52^{*}$ & 2.54 \\
\hline & Methanol & 574.82 & 1035.00 & 8.19 & 2.88 \\
\hline \multirow[t]{3}{*}{ C. roseus } & Hexane & 645.33 & 1452.88 & $2.40^{*}$ & 2.92 \\
\hline & Ethyl acetate & 1370.06 & 2089.43 & $0.96^{*}$ & 3.22 \\
\hline & Methanol & 715.39 & 1287.54 & $5.82^{*}$ & 2.96 \\
\hline
\end{tabular}

*Significant at $\mathrm{P}<0.05$ level, C. quinquefasciatus: Culex quinquefasciatus, A. fruticosa: Acalypha fruticosa

profile of larvae treated with hexane extract of A. fruticosa showed higher enzyme activities by way of intense staining of fractions both at $1 / 4$ and $1 / 10 \mathrm{LC}_{50}$ value of 48 hrs treatments (Fig. 2).

In the case of relative mobilities of $\beta$-carboxylesterase enzyme profile of larvae of $C$. quinquefasciatus treated against hexane and methanol extracts of $C$. roseus indicated higher enzyme activities in the gel, especially $24 \mathrm{hrs}$ treatment in both the concentrations of $1 / 4$ and $1 / 10$ of $\mathrm{LC}_{50}$ value (Fig. 2).

Individual band intensities of $\alpha$ - or $\beta$-carboxylesterase isozyme from the profile obtained from native PAGE gel were quantified using ImageJ $(\mathrm{NIH})$. Values in the linear range of enzyme fraction/band intensities were selected for quantifications. Samples of control and treatments (control and plant extract exposed larval samples) were run side by side on the same gel. The densitometric analysis revealed that the $\alpha$ - Est2 isozyme expression level was increased in A. fruticosa ethyl acetate extract, $C$. roseus hexane and methanol extract exposed larval samples, especially in the concentrations of $1 / 4$ and $1 / 10$ of $\mathrm{LC}_{50}$ value of $24 \mathrm{hrs}$ treatment except hexane extract of $A$. fruticosa. Likewise, $\alpha$ - Est $4 / 5$ isozymes were found to be intensely stained in $A$. fruticosa ethyl acetate extract $C$. roseus hexane and methanol extract exposed larval samples (especially $24 \mathrm{hrs}$ treatment in the concentrations of $1 / 4$ and $1 / 10$ of $\mathrm{LC}_{50}$ value) except $A$. fruticosa ethyl acetate extract exposed larvae (Fig. 3).

A. fruticosa ethyl acetate extract, and C. roseus hexane and methonal extract exposed larval samples, especially in the concentrations of $1 / 4$ and $1 / 10$ of $\mathrm{LC}_{50}$ value of $48 \mathrm{hrs}$ treatment were intensely stained in $\beta$-Est2 isozyme when compared to control (Fig. 4). Furthermore, $A$. fruticosa ethyl acetate extract and $C$. roseus hexane extract exposed larvae indicated increased quantities of $\beta$-Est $4 / 5$ isozymes in the concentration of $1 / 4$ and $1 / 10$ of $\mathrm{LC}_{50}$ value of $24 \mathrm{hrs}$ treatment when compared to control.

Total protein concentrations of larvae exposed to various plant extract treatments revealed that there were decreased levels of protein in the majority of treatments when compared to control. These values of protein were also used to express the quantity of enzymes (Fig. 5).

The $\alpha$-carboxylesterase and $\beta$-carboxylesterase in the fourth-instar larvae treated with various solvent extracts of $A$. fruticosa and $C$. roseus exhibited significantly high enzyme quantities in all the treatments when compared to control. In control, the quantity of $\alpha$-carboxylesterase was $0.89 \mu \mathrm{M}$. minute $^{-1}$. mg protein ${ }^{-1}$. It was observed to be much lower against all the treatments except $1 / 4$ of $\mathrm{LC}_{50}$ value of hexane extracts of $C$. roseus and in which it was recorded as $0.92 \mu \mathrm{M}$.minute ${ }^{-1}$.mg protein ${ }^{-1}$ (Table 3).

The quantity of $\beta$-carboxylesterases in control was observed to be $1.87 \mu \mathrm{M}$.minute ${ }^{-1}$.mg protein ${ }^{-1}$. Among various treatments, the results revealed that except a few, all the other solvent extracts of plants yielded higher quantities of $\beta$-carboxylesterases (Table 4 ).

\section{DISCUSSION}

Plant-based medicine, which uses medicinal plants as the first medicine is a general phenomenon. Every civilization on earth, through written
Table 3: Quantity of $\alpha$-carboxylesterase in the fourth instar larvae treated with various solvent extracts of plants

\begin{tabular}{|c|c|c|c|c|c|}
\hline \multirow[t]{3}{*}{$\begin{array}{l}\text { Name of } \\
\text { the plants }\end{array}$} & \multirow[t]{3}{*}{ Solvent } & \multicolumn{4}{|c|}{$\begin{array}{l}\text { Esterase activity } \\
\left(\mu M_{\text {minute }}{ }^{-1} \cdot \mathrm{mg} \mathrm{protein}^{-1}\right)\end{array}$} \\
\hline & & \multicolumn{2}{|c|}{$1 / 4^{\text {th }}$ dilution } & \multicolumn{2}{|c|}{$1 / 10^{\text {th }}$ dilution } \\
\hline & & $24 \mathrm{hrs}$ & $48 \mathrm{hrs}$ & 24 hrs & $48 \mathrm{hrs}$ \\
\hline \multirow[t]{2}{*}{ A. fruticosa } & Ethyl acetate & 3.92 & 3.68 & 4.42 & 3.64 \\
\hline & Hexane & 5.70 & 4.62 & 5.08 & 3.69 \\
\hline \multirow[t]{2}{*}{ C. roseus } & Hexane & 1.17 & 0.92 & 1.21 & 1.27 \\
\hline & Methanol & 2.96 & 1.48 & 2.24 & 2.11 \\
\hline
\end{tabular}

Control - $0.89 \mu{\mathrm{M} . \text { minute }^{-1} . \mathrm{mg} \text { protein }}^{-1}$, C. roseus: Catharanthus roseus, A. fruticosa: Acalypha fruticosa

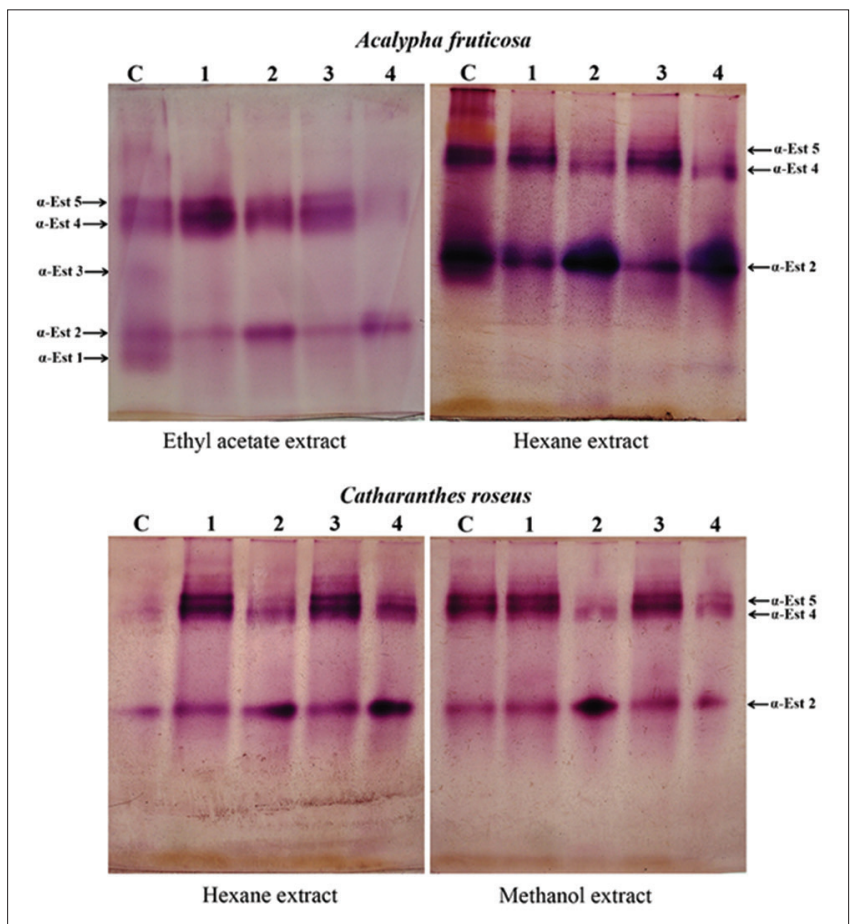

Fig. 2: $\beta$-Carboxylesterase isozyme pattern of Culex quinquefaeciatus upon exposure to different medicinal plant extracts C: Control, 1: 1/4 dilution $24 \mathrm{hrs}$, 2: 1/4 dilution $48 \mathrm{hrs}$, 3: 1/10 dilution 24 hrs, $4: 1 / 4$ dilution 48 hrs

or oral tradition, has relied on the vast variety of healing plants for their healing attributes. The majority of medicinal plant products available today, originated from the same traditional [30] traditional medicine has spread throughout the world and has gained popularity not only in the developing countries but also to industrialized countries which have access to alternative medicine [31]. The control of mosquitoes at larval stage is focused with plant extracts. The advantage of targeting mosquito at the larval stage is that they cannot escape from their breeding habitat 


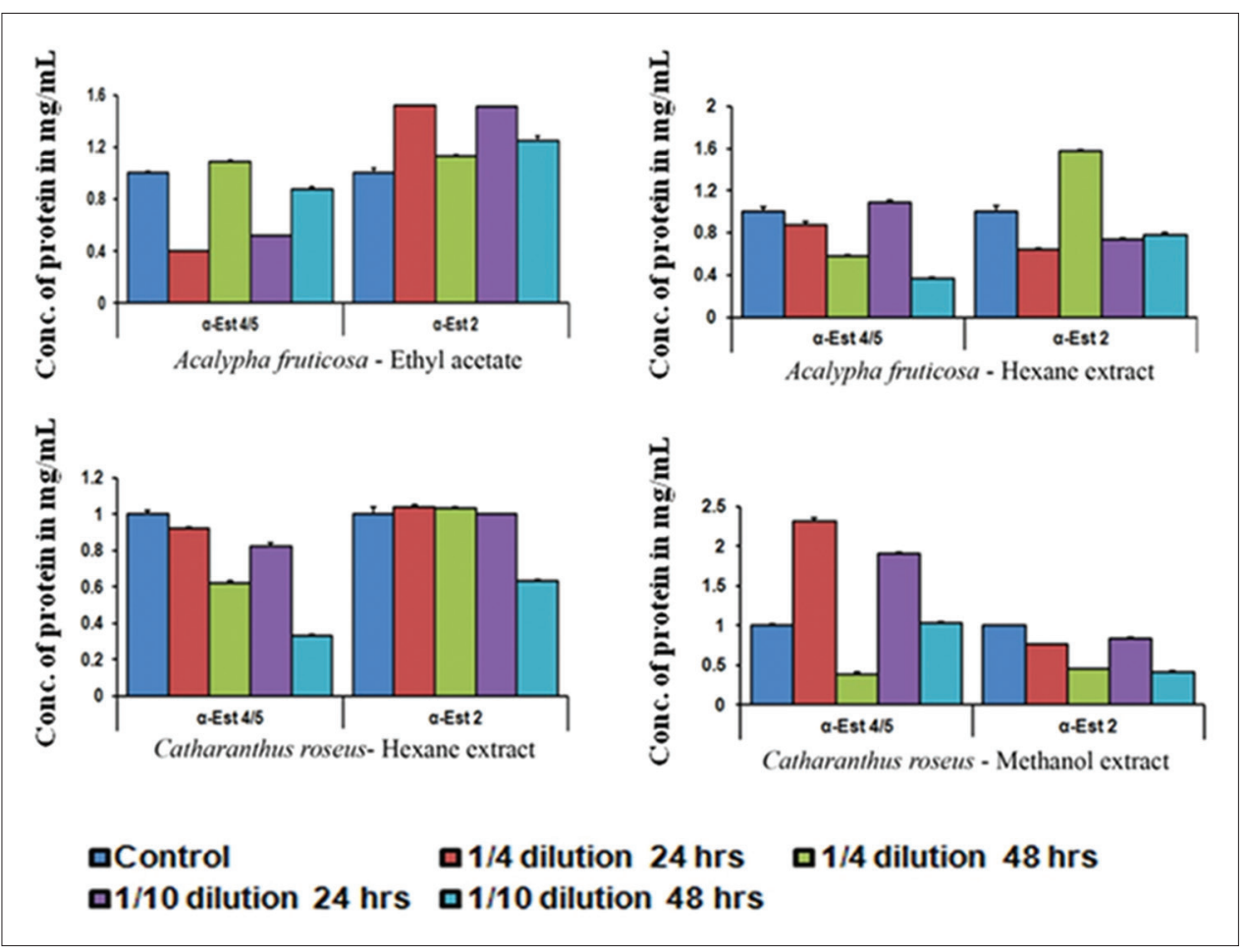

Fig. 3: Densitometry analysis of $\alpha$-carboxylesterase isozyme banding pattern by using image 1.46r software

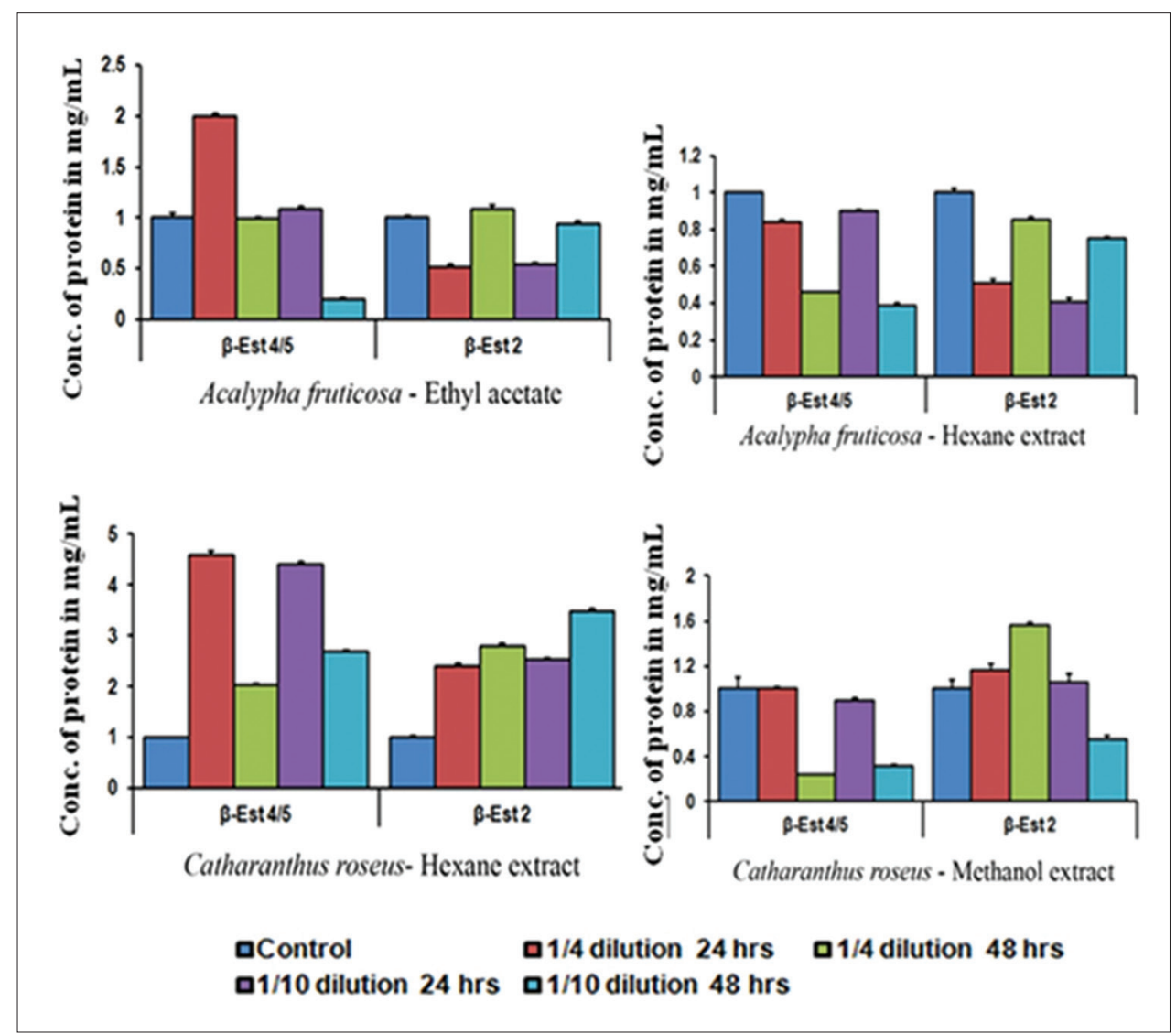

Fig. 4: Densitometry analysis of $\beta$-carboxylesterase isozyme banding pattern by using image 1.46r software

until the adult emergencies and also to reduce the overall pesticide use to control of adults by aerial application of adulticidal chemicals. The application of synthetic insecticides could be thus reduced by botanical pesticides through natural control mechanism. These botanicals are often active against a number of insect pest species, less expensive, easily biodegradable to non-toxic products and potentially suitable for use in mosquito control program [32]. Plant allelochemicals may be quite useful in increasing the efficacy of biological control agents because plants produce a large variety of compounds that increase plant resistance to insect attack [33]. Recently, bio-pesticides with plant 


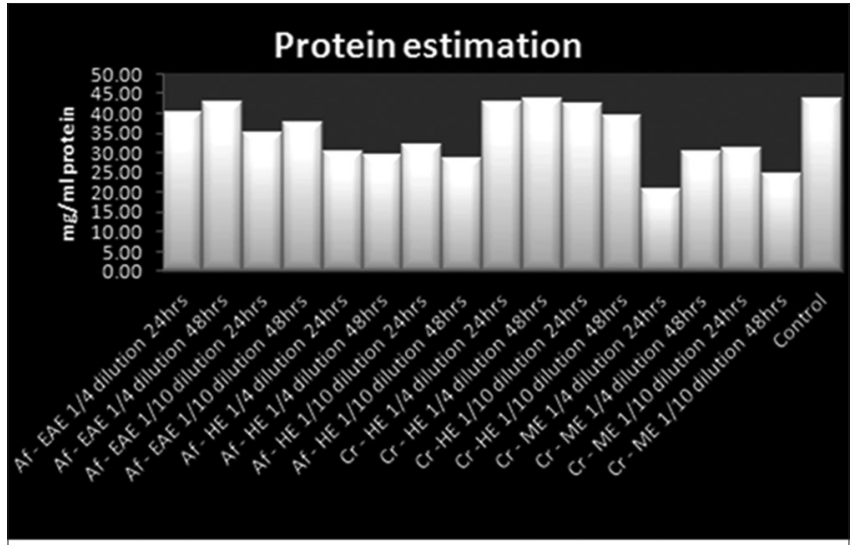

Af-EAE : Acalypha fruticosa - Ethyl acetate extract

Af-HE : Acalypha fruticosa-Hexane extract

$\mathrm{Cr}-\mathrm{HE}$ : Catharanthus roseus- Hexane extract

Cr-ME : Catharanthus roseus- Methanol extract

Fig. 5: Determination of protein concentration from whole larval homogenate

Table 4: Quantity of $\beta$ - carboxylesterase in the fourth instar larvae treated with various solvent extracts of plants

\begin{tabular}{|c|c|c|c|c|c|}
\hline \multirow[t]{3}{*}{$\begin{array}{l}\text { Name of } \\
\text { the plants }\end{array}$} & \multirow[t]{3}{*}{ Solvent } & \multicolumn{4}{|c|}{$\begin{array}{l}\text { Esterase activity } \\
\left(\mu \mathrm{M} \cdot \mathrm{minute}^{-1} . \mathrm{mg} \mathrm{protein}^{-1}\right)\end{array}$} \\
\hline & & \multicolumn{2}{|c|}{$1 / 4^{\text {th }}$ dilution } & \multicolumn{2}{|c|}{$1 / 10^{\text {th }}$ dilution } \\
\hline & & $24 \mathrm{hrs}$ & $48 \mathrm{hrs}$ & $24 \mathrm{hrs}$ & $48 \mathrm{hrs}$ \\
\hline \multirow[t]{2}{*}{ A. fruticosa } & Ethyl acetate & 1.37 & 1.90 & 3.02 & 3.13 \\
\hline & Hexane & 3.50 & 3.35 & 4.14 & 1.55 \\
\hline \multirow[t]{2}{*}{ C. roseus } & Hexane & 1.40 & 1.97 & 2.64 & 3.11 \\
\hline & Methanol & 5.53 & 3.35 & 4.70 & 2.00 \\
\hline
\end{tabular}

Control: $1.87 \mu$ M.minute ${ }^{-1} . \mathrm{mg}$ protein ${ }^{-1}$, C. roseus: Catharanthus roseus,

A. fruticosa: Acalypha fruticosa

origins are used against several insect species especially for the control of insect vectors $[34,35]$. Natural pesticides, derived from plants are more promising in this aspect. It is evident from our results that these two plants would be useful for further exploration of active compounds for the control of $C$. quinquefasciatus larvae.

The present study showed clearly that the ethyl acetate and hexane extracts of $C$. roseus and $A$. fruticosa had a prominent larvicidal effect on C. quinquefasciatus. As reported earlier in similar such studies it may be due to the presence of the phytochemicals such as alkaloids, carboxylic acids, flavanoids, phenols, proteins, quinones, resins, steroids, and saponins in the extracts of the plants [36]. In a related study conducted by Maheswaran et al. [37] on hexane extracts of leaves of Leucas aspera against the fourth-instar larvae of $C$. quinquefasciatus with $\mathrm{LC}_{50}$ values of $122.50 \mathrm{ppm}$ was reported.

The findings of the present study are quite comparable with previous reports of Maheswaran et al. [1] who have reported that the maximum larvicidal activities of different solvent leaf extracts of $L$. aspera in which hexane, chloroform and ethanol extracts showed 230.71, 518.88, and 1059.13 ppm against Aedes aegypti. Likewise, there were reports of hexane, ethyl acetate, and methanol extracts of Momordica charantia, Moringa oleifera, Ocimum gratissimum, Ocimum tenuiflorum, Punica granatum and Tribulus terrestris with promising larvicidal activity against $C$. gelidus and C. quinquefasciatus [38]. Zahir et al. [39] studied the inhibition of adult emergence and adulticidal activities of hexane, chloroform, ethyl acetate, and acetone leaves extracts of Anisomeles malabarica, Euphorbia hirta, Ocimum basilicum, Ricinus communis,
Solanum trilobatum, Tridax procumbens and seeds of Gloriosa superba against Anopheles stephensi. These studies provided a clue that there are probabilities for the presence of active principles in these plants with several solvent extracts. The larvicidal and adult emergence inhibition activities of castor ( $R$. communis) seed extract against three potential mosquito vectors $A$. stephensi, $C$. uinquefasciatus, $A$. albopictus in India studied by Mandal [8] (2010) suggest that the seed extract provided an excellent potential property for the control of mosquito vectors.

Many similar experiments on the efficacy of plant extracts on the larvicidal action on several species mosquitoes were conducted previously. The findings of the presence results, report of $50 \%$ larval mortality with some of the solvent extracts of these two plants also corroborate with earlier findings of Macedo et al. [40] who reported that the ethanol extract of Tagetes patula was able to cause only $50 \%$ larval mortality at $100 \mathrm{ppm}$ concentration.

Similarly, methanolic leaf extract of Cassia fistula was tested for larvicidal activity against $C$. quinquefasciatus and A. stephensi with $\mathrm{LC}_{50}$ values of 17.97 and $20.57 \mathrm{mg} / \mathrm{l}$, respectively [41]. The petroleum ether fraction of Acacia nolotica and Citrullus colocynthis showed 100\% mortality at 100,250 , and $500 \mathrm{ppm}$ and $60 \%$ and $50 \%$ mortality at 125 and 62.5 ppm, respectively, against C. quinquefasciatus [42]. The leaf extract of Acalypha indica with different solvents viz, benzene, chloroform, ethyl acetate and methanol were tested for larvicidal and ovicidal activity against $A$. stephensi. The larval mortality was observed after 24 hrs exposure. The $\mathrm{LC}_{50}$ values are 19.25, 27.76, 23.26, and $15.03 \mathrm{ppm}$, respectively [41]. The leaf extract of $C$. fistula with different solvents such as methanol, benzene, and acetone were studied for the larvicidal, ovicidal and repellent activity against $A$. aegypti. The $24 \mathrm{hrs}$ $\mathrm{LC}_{50}$ concentration of the extract against $A$. aegypti were observed at $10.69,18.27$, and $23.95 \mathrm{mg} / \mathrm{l}$, respectively [43]. Cheng et al. [44] reported that the leaf and bark essential oil of Cryptomeria japonica showed larvicidal activity against A. aegypti. Singh et al. [45] reported the mosquito larvicidal properties of the leaf extract of Ocinum canum against $A$. aegypti. The $\mathrm{LC}_{50}$ values for $2^{\text {nd }}, 3^{\text {rd }}$ and $4^{\text {th }}$ instar larvae were 177.82, 229.08, and 331.13 ppm, respectively. Gusmao et al. [46] reported that the extract of Derris urucu (Lonchocarpus) showed larvicidal activity against $A$. aegypti with $\mathrm{LC}_{50}$ value of $17.6 \mu \mathrm{g} / \mathrm{ml}$ which supports the present results were comparably good. Singh et al. [45] demonstrated that the larvicidal activity of $O$. canum oil tested against A. aegypti and C. quinquefasciatus (LC50 301 ppm) and A. stephensi (234 ppm).

The increased detoxification is a common mechanism of resistance to pesticides (Openoorth, 1985) [47]. In Culex pipiens, such a mechanism is often involved in resistance to organophosphates. However, the low levels of organophosphate and pyrethroid resistance could be conferred by either the elevated esterase enzymes [48]. Elevation in the $\alpha$-carboxylesterases and $\beta$-carboxylesterases are commonly found in the organophosphate resistant strains [49]. In some cases, overproduction is seen only in one type of esterase, that is, $\alpha$ - esterase or $\beta$-esterase, in others both the types are overproduced simultaneously [50]. In the present study, we have also observed an increased $\alpha$ - and $\beta$-carboxylesterase activities in $C$. quinquefasciatus to various solvent extracts of $A$. fruticosa and C. roseus. C. quinquefasciatus being an urban vector that breeds in the water stagnations might not have been exposed to various agricultural pesticides, before the introduction of plant products. This might have triggered the overproduction of both esterases through genetic selection/gene amplification. Therefore, increased tolerance to the extracts of these plants in $C$. quinquefasciatus might be a result of gene amplification of esterases through genetic selection, resulting in elevated levels of esterase activities.

\section{CONCLUSION}

The present findings on various solvent extracts of leaves of A. fruticosa leaves are promising sources for the control of $C$. quinquefasciatus larvae. It is an indigenous medicinal plant of India and is easily available to local people. It may be a safe alternative to synthetic chemicals. 
Further studies on isolation of bioactive fraction/constituent as well as application on larger scales in the field may provide promising lead products for effective mosquito control. The results of the present investigations are more or less in agreement with aforementioned findings.

\section{REFERENCES}

1. Maheswaran R, Kingsley S, Ignacimuthu S. Larvicidal and repellent activity of Clerodendron phlomides against Culex quinquefasciatus say (Diptera: Culicidae), In: Proceeding of Recent Trends in Insect Pest Management; 2008. p. 240-3

2. WHO. Pesticides and their Application for the Control of Vectors and Pests of Public Health Importance. World Health Organization, WHO Pesticides Evaluation Scheme, WHO/CDS/WHOPES/GCDPP/2006.1. Geneva: WHO; 2006.

3. WHO. Manual on Practical Entomology in Malaria, Part I. Who Division of Malaria and Other Parasitic Diseases. Geneva: WHO; 1975. p. 160

4. Piyarat SW, Freed M, Roy S. Biologically active plant extract for the control of mosquito larvae. Mosq News 1974;34:398.

5. Kalyanasundaram M, Das PK. Larvicidal \& synergestic activity of plant extracts for mosquito control. Indian J Med Res 1985;82:19-23.

6. Babu R, Murugan K. Interactive effect of neem seed kernel and neem gum extracts on the control of Culex quinquefasciatus say. Neem Newsl 1998;15:9-11.

7. Venkatachalam MR, Jebanesan A. Repellent activity of Ferronia elephantum Corr. (Rutaceae) leaf extract against Aedes aegypti (L.). Bioresour Technol 2001;76:287-8.

8. Mandal S. Exploration of larvicidal and adult emergence inhibition activities of Ricinus communis seed extract against three potential mosquito vectors in Kolkata, India. Asian Pac J Trop Med 2010;5:605-9.

9. Singh KV, Bansal SK. Larvicidal properties of a perennial herb Solanum xanthocarpum against vectors of malaria and dengue/DHF. Curr Sci 2003;84:749-51.

10. Shaalan EA, Canyon D, Younes MW, Abdel-Wahab H, Mansour AH. A review of botanical phytochemicals with mosquitocidal potential. Environ Int 2005;31(8):1149-66.

11. Sharma P, Mohan L, Srivastava CN. Amaranthus oleracea and Euphorbia hirta: Natural potential larvicidal agents against the urban Indian malaria vector, Anopheles stephensi Liston (Diptera: Culicidae). Parasitol Res 2009;106(1):171-6.

12. Hasanuzzaman $M$, Idris $A B$. Isozymes variation during development, revealed by esterase band patterns of Bactrocera carambolae. J Bio Sci 2012;1:31-5.

13. Gu X, Zera AJ. Developmental profiles and characteristics of hemolymph juvenile hormone esterase, general esterase and juvenile hormone binding in the cricket, Gryllus assimilis. Comp Biochem Physiol 1994;107:553-60.

14. Kapin MA, Ahmad S. Esterase in larval tissues of Gypsy moth, Lymantria dispar (L.): Optimum assay conditions, quantification and characterization. Insect Biochem 1980;10:331-7.

15. Kambysellis MP, Johnson FM, Richardson RH. Isozyme variability in species of the genus Drosophila. IV. Distribution of the esterases in the body tissues of $D$. aldrichi and $D$. mulleri adults. Biochem Genet 1968;1:249-65.

16. Cohen E, Sverdlov E, Wool D. Expression of esterases during ontogenesis of the flour beetle Tribolium castaneum (Tenebrionidae; Coleoptera). Biochem Genet 1977;15(3-4):253-64.

17. French-Constant RH, Byrne FJ, Stribley MF, Devonshire AL. Rapid indentification of the recently recognized Myzus antirrhinii (Macchiati) (Homoptera: Aphididae) by polyacrylamide gel electrophoresis. The Entomologist 1998;107:20-3.

18. Rachokarn S, Piyasaenghthong N, Bullangpoti V. Impact of botanical extracts derived from leaf extracts Melia azedarach L. (Meliaceae) and Amaranthus viridis L. (Amaranthaceae) on population of Spodoptera exigua (Hubner) (Lepidoptera: Noctuidae) and detoxification enzyme activities. Commun Agric Appl Biol Sci 2008;73:451-8.

19. Small GJ, Hemingway J. Molecular characterization of the amplified carboxylesterase gene associated with organophosphorus insecticide resistance in the brown planthopper, Nilaparvata lugens. Insect Mol Biol 2000;9(6):647-53.

20. Vontas JG, Small GJ, Hemingway J. Glutathione S-transferases as antioxidant defence agents confer pyrethroid resistance in Nilaparvata lugens. Biochem J 2001;357:65-72.

21. Bullangpoti V, Visetson S, Milne J, Milne M, Sudthongkong C,
Pornbanlualap S. Effects of alpha-mangostin from mangosteen pericarp extract and imidacloprid on Nilaparvata lugens (Stal.) and non-target organisms: Toxicity and detoxification mechanisms. Commun Agric Appl Biol Sci 2007;72:361-712.

22. Rattanapan J. Antioxidant Activity of Extracts from Stems Alyxis reinwardtii. M.S. Thesis, Chulalongkorn University; 2007.

23. Abbott MS. A method of computing effectiveness of an insecticide. J Econ Enotmol 1925;18:265-7.

24. Alder HL, Rossler EB. Introduction to Probability and Statistics. $6^{\text {th }}$ ed. San Francisco: W.H. Freeman Company; 1977. p. 246.

25. Finney DJ. Probit Analysis. Cambridge: Cambridge University Press; 1971. p. 333.

26. Bradford MM. A dye binding assay for protein. Anal Biochem 1976;72:248-54.

27. Van Asperen K. A study of housefly esterases by means of a sensitive colorimetric method. J Insect Physiol 1962;8:401-16.

28. Argentine JA, James AA. Characterization of a salivary gland-specific esterase in the vector mosquito, Aedes aegypti. Insect Biochem Mol Biol 1995;25(5):621-30

29. Maurer HR. Disc Electrophoresis and related Techniques of Polyacrylamide Gel Electrophoresis. Berlin, New York: Walter de Gruyter; 1971. p. 222.

30. Muhammad A, Rao MU, Ado AB, Mohd KS, Zin T. Some natural products and their secondary metabolites attributed towards diabetic cure: A review. Int J Pharm Pharm Sci 2015;7:22-8

31. Abdoul-Latif FM, Fourreh AE, Merito A, Osman DA, Said CN, Djama M, et al. Ethnobotanical knowledge of medicinal plants in dikhil, Southern Djibouti. J Pharm Pharm Sci 2016;8:247-61.

32. Alkofahi A, Rupprecht JK, Anderson JE, Mclaughlin JL, Mikolajczak KL, Scott BA. Search for new pesticides from higher plants. In: Arnason JT, Philogene BJ, Morand P, editors. Insecticides of Plant Origin. Washington, DC: American Chemical Society; 1989. p. $25-43$.

33. Berenbaum MR. Allelochemicals in insect-microbe-plant interactions: Agents provocaterurs in the coevolutionary arms race. In: Barbosa P, Lotourneau DK, editors. Novel Aspects of Insect-Plant Interactions. New York: Wiley; 1988. p. 97-123.

34. Schmutterer H. Properties and potential of natural pesticides from the neem tree, Azadirachta indica. Annu Rev Entomol 1990;35:271-97.

35. Nathan SS, Chung PG, Murugan K. Effect of botanicals and bacterial toxin on the gut enzyme of Cnaphalocrocis medinalis. Phytoparasitica 2004:32:433-43.

36. Jayanthi AC. Phytochemistry and antibacterial activity of Andrographis paniculata (Burm. f.) Wall. Ex Nees. M.Sc. Thesis, Department of Chemistry, Scott Christian College (Autonomous), Nagercoil, Tamilnadu, India; 2009.

37. Maheswaran R, Sathish S, Ignacimuthu S. Larvicidal activity of Leucas aspera (Willd.) against the larvae of C. quinquefasciatus say. and $A$. aegypti L. IJIP 2008b;2:214-7.

38. Kamaraj C, Rahuman AA, Bagavan A, Mohamed MJ, Elango G, Rajakumar G, et al. Ovicidal and larvicidal activity of crude extracts of Melia azedarach against Haemonchus contortus (Strongylida). Parasitol Res 2010;106:1071-7.

39. Zahir AA, Rahuman AA, Bagavan A, Elango G, Kamaraj C. Adult emergence inhibition and adulticidal activities of medicinal plant extracts against Anopheles stephensi Liston. Asian Pac J Trop Med 2010;8:878-83

40. Macêdo ME, Consoli RA, Grandi TS, dos Anjos AM, de Oliveira AB, Mendes NM, et al. Screening of Asteraceae (Compositae) plant extracts for larvicidal activity against Aedes fluviatilis (Diptera: Culicidae). Mem Inst Oswaldo Cruz 1997;92(4):565-70.

41. Govindarajan M, Jebanesan A, Pushpanathan T. Larvicidal and ovicidal activity of Cassia fistula Linn. leaf extract against filarial and malarial vector mosquitoes. Parasitol Res 2008;102(2):289-92.

42. Anuratha V, Lakshmi I, Sakthivadivel M, Daniel T. Effect of certain plant extracts against the fourth instar larvae of filarial vector $C$. quinquefasciatus. J Ecobiol 2000;12:93-8.

43. Govindarajan M. Bioefficacy of Cassia fistula Linn. (Leguminosae) leaf extract against chikungunya vector, Aedes aegypti (Diptera: Culicidae). Eur Rev Med Pharmacol Sci 2009;13(1):99-103.

44. Cheng SS, Chang HT, Chang ST, Tsai KH, Chen WJ. Bioactivity of selected plant essential oils against the yellow fever mosquito Aedes aegypti larvae. Bioresour Technol 2003;89(1):99-102.

45. Singh NP, Kumari V, Chauhan D. Mosquito larvicidal properties of the leaf extract of a herbaceous plant, Ocimum canum (Family: Labiatae). J Commun Dis 2003;35:43-5.

46. Gusmão DS, Páscoa V, Mathias L, Curcino Vieira IJ, Braz-Filho R, 
Alves Lemos FJ. Derris (Lonchocarpus) urucu (Leguminosae) extract modifies the peritrophic matrix structure of Aedes aegypti (Diptera: Culicidae). Mem Inst Oswaldo Cruz 2002;97(3):371-5.

47. Openoorth FJ. Biochemistry and genetics of insecticidal resistance. In: Kerkut GS, Gilbert LG, editors. Comprehensive Insect Physiology, Biochemistry and Pharmacology. Vol. 12. Oxford: Pergamon Press; 1985. p. 731-73.

48. Penilla RP, Rodríguez AD, Hemingway J, Torres JL, ArredondoJiménez JI, Rodríguez MH. Resistance management strategies in malaria vector mosquito control. Baseline data for a large-scale field trial against Anopheles albimanus in Mexico. Med Vet Entomol 1998;12(3):217-33.

49. Ketterman AJ, Karunaratne SH, Jayawardena KG, Hemingway J. Qualitative differences between populations of $C$. quinquefasciatus in both the esterases A2 and B2 which are involved in insecticide resistance. Pest Biochem Physiol 1993;47:142-8

50. Vaughan A, Hemingway J. Mosquito carboxylesterase Est-a-21 (A2). Cloning and sequence of the full-length cDNA for a major insecticide resistance gene worldwide in the mosquito C. quinquefasciatus. J Biol Chem 1995;270:17044-9. 